\title{
The Making of Water-Floating Seasonal Cuisine and Its Association to Tourism Development in An Giang Province
}

\author{
Le Thi Ngoc Diep \\ University of Social Sciences and Humanities, Ho Chi Minh City, Vietnam \\ Vietnam National University, Ho Chi Minh City, Vietnam
}

\begin{abstract}
Floods have been popularly understood as the nightmares of human beings for their devastation causes. Floods in traditional Vietnamese minds are of the same type since ancient Vietnamese used a metaphor to address the floods in Red River Delta (Hanoi area) as un-auspicious marine spirit Thủy Tinh being defeated by the inland spirit Sơn Tinh in the legendary battle of life. Therefore, as being expressed in many cultures, floods are symbol of death and loss, and human beings have always attempted to get rich of or overcome the floods. However, the floods, under the awareness and pragmatic life of the people of An Giang Province as well as the whole Mekong River Delta (in Southern Vietnam), the floods are considered as the sign of wealth and happiness. What makes the floods to be so auspiciously acknowledged, and how do people manage to "exploit" the floods to enrich their life? This paper is to investigate and generalize the approaches of utilizing the floods' resources to diversify their life, especially in cuisine culture. The research learns that the regularly stable floods in the Mekong River system strongly and positively affects the life of the local residents, and the community is further wise to exploit and transform the natural resources into their cultural world, mentally and materially, among which, ecotourism is a potentially prospective field.
\end{abstract}

Keywords: An Giang, water-floating season, cuisine, transformation, ecotourism

\section{Introduction}

An Giang is one of the 13 provinces of the Mekong Delta, a recently developed region in Southern Vietnam. It is located in the headwater area of the Mekong River where Tien and Hau tributaries flow into Vietnamese territory from Cambodia. From July to October of lunar year annually, flood waters from upstream flow down, make An Giang get flooded earlier than the rest of the delta. The water-floating season does not only bring sediment to enrich the rice-fields but also create favorable conditions for the birth and development of aquatic species and plants during the season. In addition, An Giang is home of four main ethnic groups Vietnamese, Chinese, Cham, and Khmer with their rich and diverse cultures. Taking inherited from the early Oc Eo civilization (1st to 6th century AD), An Giang enjoys its rich legacies of ancient civilization which could be wisely used as historic and cultural resources for modern development. However, these both natural and man-made sources of values are basically in their primary potentials, making An Giang a promising destination for the tourists in the future.

Le Thi Ngoc Diep, Ph.D., Faculty of Cultural Studies, University of Social Sciences and Humanities; Vietnam National University, Ho Chi Minh City, Vietnam. 
Thanks to its easy geographical features, natural conditions, and demographic diversity, Lower Mekong River Delta has dramatically formed a unique cuisine culture during the water-floating season. In comparison to all provinces sharing such a culture, An Giang, with its special features, is identified as the most typical case. The culinary style strongly expresses the imprints of the long-lasting process of reclamation, settlement, village-formation, and market-building by all four ethnic groups in this fertile land.

Foods are made primarily as a naturalistic response to the pragmatic demands of life. Especially, in the agriculture-based culture of Vietnam, foods play an important role in people's daily, concerns as our grandfathers once said, "Có thưc mói vục được đạo (All virtues come after the eating)”. Foods are not only made to provide nutrition for survival but also to fulfill the needs of spirit-worshipping, for building social communication and for molding behavioral system. Nguyen Nha (2009, p. 59) had remarked, "Dining reflects the philosophy of life, the living notation and art of living, cuisine is undoubtedly the climax of national culture”. By following this approach, one can see through the foods, the cultural mark of a nation-state, the cultural diversity of domestic regions as well as the principles of cultural formation and social transformation.

This article, under the geo-cultural perspective, studies the water-floating seasonal cuisine in An Giang province in relation to the impacts of natural environments in order to generalize the idea that natural conditions are the primarily important factors in forming the uniqueness of local cuisine culture. The research is also to pay a contribution to the developmental planning of An Giang tourism by investigating and validating the available natural resources as a precondition for the local economic development as well as to help build the typical tourism category in the province.

\section{Applying Geo-cultural Perspective in Doing Researches in Cuisine Culture}

Eating and drinking are the daily natural practices of all human beings. From the very beginning period, people looked for foods to survive from the natural environment under the basic forms of hunting and/or collecting. At this time, dinings were basically the biological activities. During the evolution of mankind, the discovery of fire and the transformation from raw into cooked food marked a turning point in human life. This invention made life changed in all aspects, including psyche, cognition, and perception.

The higher level of civilization do the human beings evolve, the higher the demands for food do they acquire. People do not only need to fulfill their biological needs in eating but also accelerate into more sophisticated norms: eating delicious and beautiful foods for healing and gaining beauty. In order to meet these criteria, cooking has been elevated to a form of art with a higher status of aesthetics, each people have created their own set of values and identical characteristics in cuisine culture.

Culinary art is undoubtedly a reflective picture of the nature, of the nation-state as well as their people's spirit, psyche, and emotions. Furthermore, food culture is also identified as the expression of both universal nature and national identity of each country. At a certain point, cuisine shows the imprints of locally geographical conditions, historical context as well as cognitive concepts and cultural characteristics of a nation or a people. The formation of cuisine style of a region or a nation is thus a contextualized absorption of living experience and lifestyle building of the residents.

As a matter of fact, culinary culture has absorbed the creativity of the people and accumulated values from different communities and localities through the eating behavior and during the in interaction with both natural and social environments. Culinary culture is also the most honest reflection of the economic, cultural, and social life of a community. 
Studying the relationship between geography and culture has been on the rise since the pre-modern periods. The viewpoint of geographic determinism from the ancient times to 19th century alluded to the fact that nature was an important factor which dominated all aspects of human life. By the 20th century, with the development of science and technology, especially in the field of cultural studies, the doctrine of "Neo geo-culture" has been born in replacement of the old-fashioned "environmental determinism"; it emphasizes the interactions between natural landscapes and the people through which the cultural landscapes are created. The new viewpoint emphasizes the role of human beings; the nature is no longer the uniquely decisive and one-way dominant factor. People are able to pay back the impacts to the environment or to choose the best environment for their own adaptation.

In Vietnam, the well-known researcher Dao Duy Anh (2000, p. 14) once commented that "The way of living of people, meaning the culture, has a very close relation to natural conditions ... we have to study the natural background of that country first”. According to the author Tran Ngoc Them (2006, p. 29), "People live in close relationship with nature ... In dealing with the natural environment, there will be two possibilities: the useful resources are always being taken advantage, while the harmful matters are being wisely confronted with”. Tran Quoc Vuong (2005, p. 150) said that

The nature is the starting point of Vietnamese culture. Culture is the adaptation and transformation of nature. Nature sets before the people the challenges. Culture is the product of the man, the reflection, the response of the man to the challenges of nature.

It is the impact of nature that makes the men always look for the ways to adapt and cope with, especially in cuisine. In consideration to the relationship between the natural environment and culinary culture, many researchers have long concerned and discussed for a long time. Most scholars focused on geo-cultural factors in these studies, thus building a distinct cultural identity of Vietnamese cuisine.

\section{The Floods as Special “Gift” From the Nature in An Giang}

An Giang has got a special topography of both river-delta plain and mountainous hills. The plain, in turn, consists of two sub-types: alluvial and low mountainous plains. An Giang has silt of two big river tributaries, the Tien and Hau rivers, where the alluvial comes from, as well as a number of ponds, lakes, river-ways, streams and the canals, etc., all creating a special ecosystem. In addition to the primary function of transportation and irrigation, these river-based landscapes also provide people with various kinds of aquatic products.

There is a group islet along the Tien River, Hau River, and part of Vam Nao River that links both rivers together are well-known for growing crops and short-term industrial plants useful for making handicrafts and daily goods for use. In the past, the villagers, especially in Tan Chau, Phu Tan and Cho Moi districts, planted mulberry for silk-making. This tradition has been narrowed these days, however, the remains are currently considered as the precious legacies under the newly-born tourism promotion policy. Regarding forest resources, An Giang has got over 583 ha of natural forest, mainly located around the Seven Mountains. These beautiful mountainous sceneries, in combination with the locally cultural and historical relics, make An Giang the province of most diversity and prospect in the region.

An Giang enjoys the monsoon tropical climate with two distinct rainy and sunny seasons, year-round temperatures are slightly changed and are favorable for agricultural development and handicraft production. To 
compare with the provinces located at most downstream of the Mekong River where sea water often penetrates the fields during the monsoon season causing damages in agriculture, An Giang has never confronted this sea water attack so far. However, the province is heavily dependent on the water supply by the Mekong River. Every year, the water flows from the uplands into the delta, making the surrounding fields flooded, and thus forming the water-floating season. In the season, nearly 70\% of natural land area of An Giang gets flooded up to four or five months (usually from lunar May/June to October/November annually). Surprisingly, local residents are not only accustomed to "living with the flood"; furthermore, the water-floating season is also considered to be the positive livelihood season. Previously, people based on collecting the natural resources during the season, nowadays do they learn to cultivate and produce flood-based products, such as vegetable and fish by making use of canals, ponds, and fields. Due to the location and the geographical conditions of the land, the floating season is "a gift" from Mother Nature. Floating season cuisine has drifted deep into the mind of the people as we see in this saying: "Fields filled with birds and lakes densely occupied by fishes".

\section{Water-Floating Seasonal Cuisine as the Empowered Imprints of the Interaction Between Men and Their Land}

Many of the transformations are implemented on the basis of context-based interaction. Robert P. Weller (1987, pp. 5-7) argued that "Much culture [...] is neither strongly institutionalized nor strongly ideologized. It exists instead as a process of pragmatic interpretation and re-interpretation”. After three centuries of getting familiar with the stability and regularity of the annual water-floating season, the local residents have composed a special cuisine system reflecting both two basic procedures in human life: exploiting and transforming the nature.

Firstly, the water-floating seasonal cuisine is seen as the outcome of the basic exploitation in the new land. An Giang is affected by tropical monsoons, so the ecosystem of plants and animals in the province during the floating season follows this principle. As An Giang is the sub-region of diverse topography and ecology, the floating season has further given preference to this land with extremely rich and various products. With such favorable conditions, local residents have made full use of the aquatic environment for meals more abundant. During the floating season, many natural vegetables grow in rich and various conditions. Due to the hot sunny climate, local residents love eating raw vegetables, thanks to the abundant resources. From the inland vegetables in the water season, such as flowers of common sesban, sprouts of polypody plant, sprouts of wild maracuja, river-leaf creeper, leaves of neem, leaves of creek premna, leaves of piper lolot, blumea lacera, sprouts of gourd, and sprouts of squash, as well as underwater vegetables, such as water-lily, water chestnut, water hyacinth, sprouts of luffa cylindrical, variegated boat lily, typha orientalis, uygun neticeler, Chinese chives, water mimosa ... and a lot of other vegetables are always available. Wild vegetables have become familiar materials for food as an indispensable ingredient in meal structure in An Giang and the whole region. These vegetables used as foods in the season lively prove a unique feature of local cuisine in An Giang province. Among them, flowers of common sesban have become a typical image for the water-floating season; most of the dishes use the flowers as main ingredients. Nowadays, due to high consumption demand, many families cultivate common sesbans in the abandoned areas for commercial purposes.

Thanks to the water from the upper reaches of the Mekong River, numerous aquatic species from the Tonle Sap lake (Cambodia) flow into the plain, with extremely rich species, such as ca linh fish, dory, kryptopterus, featherback, wallago attu, monkfish, catlocarpio siamensis, catfish, snakeskin gourami mystus, loach, etc., various shrimps and other sea-aqua foods, such as ocypodidae, crabs, sesarmidae, frogs, eels, 
oysters, clams, snails, etc. find their ways to the region. As for reptiles, diversity of species, such as snakes, salamanders, litchis, lizards, etc. fulfill An Giang's natural ecosystem in mass quantity, thus facilitating the growth of bird species. Birds is not in large quantity but in quite diverse types: bats, storks, herons, cormorant, blackbird, anatidae, gallirallus striatus, rallidae, gallicrex cinerea, etc.

Among the aquatic products during the floating season, ca linh has become a specialty, the main ingredient of many dishes in An Giang. From the upper reaches of Mekong River system, ca linh moves according to the tide, grow up with the abundant floating foods in the water. When they come to the territory of An Giang, they are of the most delicious period, especially at the early season. In order to catch the little ca linh fish, people have to put the nets down to the bottom in the river at the headwaters' areas. Following the tide, ca linh widespread throughout the region, and grow very fast. Once they grow old, they are not a favorable cooking ingredient anymore because their hard bones may challenge any diners. Undoubtedly, the floating season has become an important livelihood season for the local residents in An Giang and Mekong River Delta.

With diverse and rich aquatic products, the local residents have exploited fish, reptiles, and plants from floating waters to enrich their cuisine tradition. The water-floating season has created abundance and diversification on the raw materials for cooking, marking the deep imprint of natural ecological environment in human society and culture.

Secondly, the water-floating seasonal cuisine deeply absorbs the early history of land reclamation. Since the arrival of Vietnamese newcomers to the new land of the Mekong River Delta, there have been so many incentives and challenges waiting ahead. The nature was still wild, so people had to take advantage of all resources available in the local nature to survive. Such eating and drinking conditions gradually formed the habit and became a part of the culinary culture of the local residents, molding the characteristics and features in way of life, behavior, daily activities especially during the water-floating season.

For the people of An Giang, as mentioned above, the water-floating season is considered as a gift from the Mother Nature. The available cooking materials during the floating season partially present the legacies and imprints of the early period of land acquisition: wild-based and simple in materials, naturalistic in flavor, and instantly cooked. The food decoration was not sophisticated, people took advantage of the available stuffs from home garden, such as young lotus leaves, banana leaves laid down as a wild food trays on the ground. There were no tables and chairs needed, all what people needed was a place under the tree shadow with the cool wind, normally just on the soil dunes next to the fields, the canal, or on the sampan floating in the water. Such a wild but poetic manner has shaped a part of personality of the local residents.

At the beginning of the acquisition of this land region, the land exploitation was considered the most important part of people's life. Therefore, the local people did not care much about how to eat but what to eat so that they were full of energy for the next heavy works. Local people described such a harsh living condition in their folk songs, here comes a part: "Mosquitoes resound like flute blowing, leeches swim like rice-made spaghetti rolls; crocodiles occupy the river while the tigers' feet are found wide on land”. On order to survive, the people were always uniting, mutually protected and covered each other. They had to adjust themselves to be flexible and tolerant to be well-adapted to such a living environment. Since then, there have been a number of simple and unique cooking methods formed with the region. They are the dishes made from raw materials found directly in the living place, where snakehead fish or snake can be grilled wild, dry cooked goby, fried shrimps with salted chili, raw vegetable as well as simple soup cooked with vegetables around the garden can 
make a nutritive meal daily. Being identified as the absorption of the nature into cuisine culture, vegetables are actually indispensable component in the meal since the early period of land acquisition.

An Giang with rich natural resources and diverse aquatic products during the water-floating season is early well-known for other culinary ingredients: the drying fish and salty fish sauce. The most famous fish sauce is found in Chau Doc city of An Giang Province. The floating water brings ca linh fish to Chau Doc; fish sauce made from ca linh is thus popularly delicious. The flowers of common sesban are found yellowed the surface of the water, so people do not miss cooking soup of flowers of common sesban with little ca linh fish (or shrimp in replacement) for meals. Images of good homemade foods with the produces given from the nature will always be filled in mind, in the memory of those who are away from home.

\section{Creating New Imprint for the Seasonal Cuisine: The Potential Ecotourism Commodities}

In the context of integration and globalization nowadays, along with the development of socio-economy, tourism has become an essential need in human life. There are many types of tourism that are of interest in the development of tourism in contemporary Vietnam. One of them, strongly growing nowadays, is the conflating tourism between ecosystem and cultural tradition which inspires the post-modernist tourists in searching cultural identity and tradition of local community in their connection with the land and the history.

An Giang is an inland region with great potentiality for the development of ecological and cultural tourism, strongly meeting the conditions of natural resources, such as forest-based, river- and lake- based, and garden ecological tourisms, etc. Ecotourism development in An Giang is important not only for promoting economic development, creating employment opportunities, increasing incomes, and raising people's knowledge and sense of responsibility for local communities, but also producing special significances for the sustainable development of the tourism industry from the point of view of combining biodiversity and community culture in which environmental protection is an essential factor.

During a journey, dining activities are seen as important products which largely contribute to the success and the effectiveness of tourist activity. Floating season cuisine can bring visitors the real experience and opportunity for participation in the processing of dishes before enjoying them in a water-based fields' space. In such a plan, the An Giang is actually in fond of water-floating seasonal cuisine. The following part specially demonstrates the typical foods embedded the imprints of water-floating season that attract the most tourists these days.

\section{Ca linh Fish-Made Foods}

Ca linh fish offers rich nutrients, can be cooked easily into many attractive and delicious dishes. There are two types of ca linh are identified according to their age: young fish with soft bone, and older fat fish with harder bones. The first famous dish is the sour hotpot made of young and fresh ca linh soup and common sesban flowers. The soup is enriched by adding pork bones or fresh coconut juice. When eating, people deep ca linh and the common sesban flowers (or bean sprouts, sesbania, lady's finger, limnocharis flava, water-lily, etc.) in the hotpot before serving. Ca linh hotpot must be deliciously served with pure fish sauce mixed with chili. The second dish is made by salty steaming ca linh with pepper, serving with sour salad made by water-lily, banana flower, flowers of common sesban, limnocharis flava, polypody plant sprouts, etc. When cooking ca linh, one may add sugar cane for making it sweeter. Similarly, ca linh can be grilled as a favorite and attractive dish during the season. 


\section{Snakehead Fish-Made Foods}

Snakehead fish contains sweet taste with healthy, rich in minerals and vitamins, non-toxic, low-fat, and low-cholesterol meat. They are identified as one of the most nutritious foods that can cure some light diseases, or be used for increase digestive effect and anti-aging capacity.

Soup made by snakehead fish and endive is a folk-flavored dish of the local residents during the floating season. For snakehead fish, they prefer choosing the big ones, after making clean, they marinate with spices to make the fish fragrant. In some places, people fry the fish in deep oil for shrinking and absorbing spices before cooking in the rice soup. In the other places, people cut the fish into thin fillets, absorb them with spices. They put some slices of fish at the bottom of the big bowl then ladle the hot, well-cooked rice soup in for serving. By doing this way, the fish fillet is medium-cooked; people can eat it deliciously with endive growing around the home garden, in the field, or on higher mounds. In addition, snakehead fish can be also made into many other special, nutritious and attractive dishes, such as grilled snakehead fish, snakehead fish steamed with fish sauce, sweet and sour steamed snakehead fish, fish broth, etc.

\section{Common Sesban Flowers-Made Foods}

Common sesban flowers are often referred as "floating yellow apricot" in the Mekong River Delta. In the upstream districts of An Giang Province, during the annual floating season, the common sesbans are in mass blooming as to welcome the water. Common sesban is described as a simple, rustic flower species just like the personality of the Mekong River Delta residents. Taking it for food has been marked as bringing the nature closer to the people and bringing the people closer to their homeland. All common sesban parts can be used to prepare food: The leaves can be eaten like vegetables, or cooked with white tiny shrimp, anabas as soup; the nuts are used to make sprouts; the flowers, of course, are almost popular in most dishes locally. The common sesban flowers can be also fried with tiny shrimp as salad, to make Vietnamese pancake, to cook broth with ca linh, or to fry with eggs, beef or pork, etc. The flowers of common sesban have been identified as herbal food with cooling effect, detoxification, useful for people with depression, little eating, and sleeping.

Practically, the seasonal cuisine is identified as an advantage for tourism development in An Giang, meeting the needs of being harmonious in the nature of modern tourists, In addition, it is combined with other values, such as traditional culture, religious values, ethnic history, etc., and all are mutually interactive to enrich the tourism of An Giang.

Nowadays, tourism is no longer understood simply and purely as enjoying and experiencing, however, it is necessary to see the roles of the man and their wisdoms to harmonize both nature and human society together as one through the tourist activities. The main purpose of human activities, including tourism, determines the existence and sustainable development of the "natural-human-society” triangle system.

\section{Conclusion}

In conclusion, the natural environment has had a great impact on the culinary culture of the Mekong River Delta in general and in An Giang in particular, especially during the water-floating season. The water-floating seasonal cuisine in An Giang clearly reflects the close relationship between the people and the nature. In the process of matching to the South, conquering the harshness and challenges to survive in this land, the local residents clearly show their attitude towards the nature as well as their relationship with the nature. People have made use of the abundant produces given from the nature (the rivers, lakes, and floating water), wisely selected 
and created many dishes suitable to the living conditions of the new living place. This adaptation process has also shown the creativity and flexibility of the people, creating An Giang special and unique characteristics in culinary culture-the culture of the people in the new land full of both incentives and challenges.

Putting cuisine in association with tourism is a positive direction which have already had orientated plan and vision. Therefore, the provincial leaders need to invest to build the culinary festival during the floating season into a brand name that is popularized among the tourists. Hopefully, in the future, the water-floating seasonal cuisine tourism in An Giang can pay positive contribution to the improvement of life of both the tourists and local residents.

\section{References}

Anh, D. D. (2000). Vietnam's cultural history. Hanoi: Writers Association Publishing House.

Anh, H. (2017). Charming with an cuisine identity of An Giang. September 26, 2017, from http://vietnamnet.vn/vn/doi-song/du-lich/dam-da-ban-sac-voi-am-thuc-an-giang -117933.html

Caarter, G. F. (1982). Man and the land, culture geography. New York, N.Y.: McGraw Hill.

Huy, X. (2004). Culinary culture and Vietnamese cuisine (2nd ed.). Ho Chi Minh City: Youth Publishing House.

Nam, S. (2007). History of Southern reclamation. Ho Chi Minh City: Youth Publishing House.

Nha, N. (2009). The culinary identity of Vietnam. Hanoi: News Publishing House.

Nhat, V. T. (2017). Southern Cuisine worrying endlessly the original flavor. Retrieved September 26, 2017, from http://metinfo.blogspot.com/2008/01/m-thc-nam-b-au-u-hng-v-ci-ngun .html

Snakehead fish soup with endive. (2017). Retrieved September 26, 2017, from http://afamily.vn/an-ngon/chao-ca-loc-rau-dang

Southern reclamation cuisine. (2017). Retrieved September 26, 2017, from http://www.binhquoiresort.com.vn/index.php?mod=10\&grand_id=2\&parent_id=33

The attractive dishes from the flowers of common sesban. (2017). Retrieved September 26, 2017, from http://bepvang.org.vn/tin-tuc/am-thuc-va-cuoc-song/vietkings-gioi-thieu-nhung-mon-an-hap-dan-tu-bong-dien-dien

Them, T. N. (2006). Discovering Vietnamese cultural Identity: View of system and typology. Ho Chi Minh City: Ho Chi Minh City Publishing House.

Thinh, N. D. (2010). Discovering Vietnamese traditional cuisine. Ho Chi Minh City: Young Publishing House.

Vuong, T. Q. (2005). Human and cultural environment. Hanoi: Culture and Information Publishing House and Culture Institute. Weller, R. P. (1987). Unities and diversities in Chinese religion. London, Macmillan/Seattle: University of Washington Press. 